\title{
The effects of ACTH4-10 on rats' intakes of a sweetened alcoholic beverage
}

\author{
LARRY D. REID, CHRISTOPHER A. AMENDOLA, \\ CRISTI L. DELONG, and CHRISTOPHER L. HUBBELL \\ Rensselaer Polytechnic Institute, Troy, New York
}

\begin{abstract}
Standard laboratory rats were maintained on a daily regimen involving $22 \mathrm{~h}$ of deprivation of fluids followed by a 2-h opportunity to take water and a sweetened alcoholic beverage. The rats initially took very little of the alcoholic beverage, but after about 3 or 4 weeks they were taking about 2.0-2.5 g/kg of ethanol daily . This level of intake remained stable across subsequent daily opportunities. On the 37 th day of the regimen, all subjects received a placebo prior to the opportunity to take fluids. On the next 2 days, the rats received $0,1,3,10$, or $30 \mathrm{mg}$ of ACTH4-10 prior to the drinking session. No dose of ACTH4-10 reliably modified the rats' intakes of the alcoholic beverage or water. This is in contrast with the report of Krishnan, Nash, and Maikel (1991) that $30 \mu$ of ACTH4-10, given daily, reliably reduced 24-h intake of alcohol across an 8-day period.
\end{abstract}

Recently, evidence has emerged in support of the idea that it is possible to improve the treatment of alcohol abuse and alcoholism by prescribing drugs whose effects decrease the motivation to consume alcoholic beverages (Naranjo \& Sellers, 1985, 1992; Reid, 1990). Only a few drugs, such as naltrexone (an antagonist at opioid receptors) (O'Malley et al., 1992; Volpicelli, O'Brien, Alterman, \& Hayashida, 1990) and serotonin reuptake inhibitors (Naranjo, Kadlec, Sanhueza, Woodley-Remus, \& Sellers, 1990), have been shown in clinical trials to modify the propensity of alcoholics to take alcoholic beverages. Yet the results of these few trials, along with certain theoretical considerations, combine to support the suggestion that the effects of drugs can be efficient adjuncts to other treatments for alcohol abuse and alcoholism.

A number of drugs either have been shown in limited testing with rats to decrease intakes of alcohol, or, for theoretical reasons, might be likely to reduce motivation to take alcoholic beverages. For a wide variety of obvious reasons, there are more limitations on testing such drugs' effects on people rather than rats. Therefore, it follows that testing with rats can be more extensive. Also, it seems that testing with rats should involve a number of kinds of procedures, before tests with people are attempted. The present testing was done with the idea that further testing of any compound shown to be effective in reducing the intake of alcoholic beverages in rats should be submitted for further testing.

A salient issue centers on how to get rats to voluntarily take sufficient amounts of ethanol to make a test meaning-

These procedures were supported by a gift from Biomeasure Incorporated and by Grant DAO4440 from the National Institute on Drug Abuse. Correspondence should be addressed to L. D. Reid, Department of Psychology, Rensselaer Polytechnic Institute, Troy, NY 12180-3590. ful. In the test reported here, involving standard laboratory rats, a number of setting conditions are programmed (for reviews, see Hubbell \& Reid, 1990; Reid \& Hubbell, 1992). These setting conditions (providing days of opportunity to drink, provisioning a palatable alcoholic beverage, having a schedule of deprivation, and "disruption" of circadian rhythm) combine to develop stable, meaningful amounts of intake of ethanol. Although features of these setting conditions may be concordant with the kinds of setting conditions that are extant among alcoholics, it can be concluded that it is not critical that they be concordant. What is critical is that multiple setting conditions combine to produce high intakes of ethanol. It is generally believed that a drug that reduces rats' highly motivated drinking of an alcoholic beverage (without reducing intakes of concurrently presented water) is more apt to be effective in treating alcohol abuse and alcoholism than is a drug that reduces rats' weakly motivated drinking (Hubbell \& Reid, 1990). In brief, we believe that conclusions drawn from the testing described here have predictive validity.

Any controversy concerning the kind of arrangements used with rats for preclinical screening emerges into a problematic issue when two different arrangements lead to different conclusions. ACTH4-10, a metabolic product of ACTH (adrenocorticotropic hormone), has been shown, at some of the doses used here, to reliably modify some features of behavior (Bohus, 1979; de Wied \& Jolles, 1982; de Wied, Witter, \& Greven, 1975, Fekete \& deWied, 1982; van Nispen \& Greven, 1982; Witter, Greven, \& de Wied, 1975). With the reporting of these data, a problematic issue emerges because our results indicate that injections of ACTH4-10 have virtually no effect on rats' propensity to take alcohol, whereas another report (Krishnan, Nash, \& Maikel, 1991) indicates that ACTH4-10 does reduce intake of alcohol. 


\section{METHOD}

\section{Subjects}

The subjects were 60 male Sprague-Dawley rats (Taconic Farms, Germantown, NY), weighing about $200 \mathrm{~g}$ when purchased. Upon arrival at the laboratory, they were housed individually in standard hanging cages in a windowless room maintained at $22^{\circ} \mathrm{C}$ with lights on for $12 \mathrm{~h}$ a day beginning at $0900 \mathrm{~h}$. The subjects had free access to food across all procedures. Initially, they had free access to water, but 5 days after their arrival, they were placed on a daily regimen, described below, involving limited access to fluids.

\section{Drug and Solutions}

ACTH4-10 (Met-Glu-His-Phe-Arg-Trp-Gly) was tested in doses of $1,3,10$, and $30 \mu /$ rat given intraperitoneally, $15 \mathrm{~min}$ before the rats' opportunity to drink. Physiological saline, the carrier of ACTH4-10, served as a placebo. The dose of $30 \mu /$ rat was that used by Krishnan et al. (1991).

Each $100 \mathrm{~g}$ of the alcoholic beverage contained $12 \mathrm{~g}$ of pure ethanol, $0.25 \mathrm{~g}$ of saccharin, and $87.75 \mathrm{~g}$ of tap water. Both tap water and the alcoholic beverages were presented in glass bottles equipped with ballpoint sipping tubes that controlled spillage and evaporation.

\section{Procedure}

As mentioned, the rats were on a daily regimen. The regimen involved $22 \mathrm{~h}$ of fluid deprivation followed by a 2 -h period of access to water and the alcoholic beverage between 0950 and $1150 \mathrm{~h}$. The daily regimen was extant for 37 days before the formal procedures began.

On Day 38, all rats were given the placebo. The rats were then randomly assigned to one of five groups $(n=12)$, with the exception that the mean intake of ethanol was nearly the same for each group. On each of the next 2 days, one group again received the placebo while the other groups received one of the doses of ACTH4-10 (each group received the same dose on each day). The assignment of doses, including the $0-\mu$ dose or the placebo, to groups was random. So, there was a day

Table 1

Intake of Alcoholic Beverage

\begin{tabular}{ccccccccc}
\hline & \multicolumn{9}{c}{ Day } \\
\cline { 2 - 3 } Dose of & \multicolumn{2}{c}{ Placebo } & & \multicolumn{2}{c}{ Drug 1 } & & \multicolumn{2}{c}{ Drug 2 } \\
\cline { 2 - 3 } \cline { 7 - 8 } ACTH4-10 & $M$ & $S E$ & & $M$ & $S E$ & & $M$ & $S E$ \\
\hline 0 & 5.54 & 0.76 & & 5.81 & 0.64 & & 5.81 & 0.75 \\
1 & 5.48 & 0.60 & & 5.96 & 0.82 & & 6.05 & 0.64 \\
3 & 5.58 & 0.72 & & 7.14 & 0.69 & & 6.08 & 0.86 \\
10 & 5.83 & 0.73 & & 6.14 & 0.68 & & 6.20 & 0.76 \\
30 & 6.02 & 0.93 & & 6.38 & 0.76 & & 6.42 & 0.66 \\
\hline
\end{tabular}

Note-Intakes are in grams. Doses are in micrograms/rat. On the day of the placebo, all rats received injections of physiological saline. On the days of the drug, the rats received one of the doses of ACTH4-10. The interaction term yielded from the ANOVA of these data is $F(8,110)=0.42, p=.91$.

Table 2

Intake of Water

\begin{tabular}{ccccccccc}
\hline & \multicolumn{9}{c}{ Day } \\
\cline { 2 - 5 } Dose of & \multicolumn{2}{c}{ Placebo } & & \multicolumn{2}{c}{ Drug 1 } & & \multicolumn{2}{c}{ Drug 2 } \\
\cline { 2 - 5 } \cline { 5 - 8 } ACTH4-10 & $M$ & $S E$ & & $M$ & $S E$ & & $M$ & $S E$ \\
\hline 0 & 12.93 & 1.06 & & 15.94 & 1.17 & & 13.38 & 0.86 \\
1 & 14.57 & 0.83 & & 14.37 & 0.88 & & 13.49 & 0.84 \\
3 & 15.05 & 0.98 & & 14.31 & 1.33 & & 14.93 & 0.90 \\
10 & 11.89 & 0.75 & & 14.54 & 1.19 & & 13.83 & 1.04 \\
30 & 12.76 & 0.64 & & 14.84 & 1.02 & & 12.93 & 1.01 \\
\hline
\end{tabular}

Note-Intakes are in grams. Doses are in micrograms/rat. On the day of the placebo, all rats received injections of physiological saline. On the days of the drug, the rats received one of the doses of ACTH4-10. The interaction term yielded from the ANOVA of these data is $F(8,110)=1.87, p=.07$.
Table 3

Proportion of Total Fluid Taken As Alcoholic Beverage

\begin{tabular}{|c|c|c|c|c|c|c|}
\hline \multirow{3}{*}{$\begin{array}{c}\text { Dose of } \\
\text { ACTH4-10 }\end{array}$} & \multicolumn{6}{|c|}{ Day } \\
\hline & \multicolumn{2}{|c|}{ Placebo } & \multicolumn{2}{|c|}{ Drug 1} & \multicolumn{2}{|c|}{ Drug 2} \\
\hline & $M$ & $S E$ & $M$ & $S E$ & $M$ & $S E$ \\
\hline 0 & 0.30 & 0.04 & 0.27 & 0.03 & 0.30 & 0.04 \\
\hline 1 & 0.27 & 0.03 & 0.29 & 0.04 & 0.31 & 0.03 \\
\hline 3 & 0.27 & 0.04 & 0.34 & 0.04 & 0.29 & 0.04 \\
\hline 10 & 0.32 & 0.04 & 0.31 & 0.04 & 0.31 & 0.04 \\
\hline 30 & 0.31 & 0.04 & 0.31 & 0.03 & 0.33 & 0.02 \\
\hline
\end{tabular}

Note-Proportions are calculated by dividing grams of alcoholic beverage taken by grams of total fluid taken. Doses are in micrograms/rat. On the day of the placebo, all rats received injections of physiological saline. On the days of the drug, the rats received one of the doses of ACTH4-10. The interaction term yielded from the ANOVA of these data is $F(8,110)=1.06, p=.40$.

Table 4

Grams of Ethanol Taken Per Kilogram of Body Weight

\begin{tabular}{|c|c|c|c|c|c|c|}
\hline \multirow{3}{*}{$\begin{array}{c}\text { Dose of } \\
\text { ACTH4-10 }\end{array}$} & \multicolumn{6}{|c|}{ Day } \\
\hline & \multicolumn{2}{|c|}{ Placebo } & \multicolumn{2}{|c|}{ Drug 1} & \multicolumn{2}{|c|}{ Drug 2} \\
\hline & $M$ & $S E$ & $M$ & $S E$ & $M$ & $S E$ \\
\hline 0 & 2.01 & 0.29 & 2.12 & 0.23 & 2.14 & 0.29 \\
\hline 1 & 1.96 & 0.23 & 2.13 & 0.33 & 2.11 & 0.22 \\
\hline 3 & 1.98 & 0.25 & 2.53 & 0.25 & 2.13 & 0.31 \\
\hline 10 & 2.07 & 0.26 & 2.18 & 0.24 & 2.19 & 0.27 \\
\hline 30 & 2.12 & 0.29 & 2.33 & 0.27 & 2.29 & 0.22 \\
\hline
\end{tabular}

Note-Doses are in micrograms/rat. On the day of the placebo, all rats received injections of physiological saline. On the days of the drug, the rats received one of the doses of ACTH4-10. The interaction term yielded from the ANOVA of these data is $F(8,110)=0.38, p=.93$.

when all subjects received the placebo and there were 2 days when most subjects received a dose of ACTH4-10.

\section{Measures, Data Reduction, and Statistics}

The rats were weighed about $1 \mathrm{~h}$ before they were given the opportunity to drink. The intakes of fluids were tabulated by weighing the bottles before and after their presentation and finding the difference between the weights, corrected for spillage. Body weights and intakes were measured to the nearest $0.1 \mathrm{~g}$. From these data (body weights, and grams of alcoholic beverage and water taken), the number of grams of ethanol taken per kilogram of body weight and the proportion of total fluid taken as alcoholic beverage were calculated. Each kind of score was then used to determine the effects of injections. The array of each kind of score conforms to a $5 \times 3$ repeated measures analysis of variance (ANOVA), with the 5 groups (corresponding to doses) and the 3 days of injections as factors.

\section{RESULTS AND DISCUSSION}

The results are summarized in Tables 1-4. The rats took a mean of $5.69 \mathrm{~g}$ of the alcoholic beverage on the day when they all received the placebo, for a mean of $2.03 \mathrm{~g} / \mathrm{kg}$ and a mean proportion of 0.30 . The ANOVAs associated with each measure indicated that there were no reliable effects of the procedures (see Tables 1-4). Inspection of data obtained on days following injections failed to reveal any systematic effects of ACTH4-10.

On the surface, the finding that ACTH4-10 had no observable effect in our testing is different from the finding of Krishnan et al. (1991) that ACTH4-10 reduced 6 of 6 rats' intakes of a saccharin flavored alcoholic beverage. There are two notable differences between the pro- 
cedures of Krishnan et al. and ours. Our rats had only a 2-h period to drink daily, in contrast with the 24-h/day opportunity provided by Krishnan et al. The dose of ACTH4-10 was given only before two daily drinking sessions, in contrast with the eight daily doses given by Krishnan et al. There were also other differences between the two tests, such as in the strains of rats and the kinds of alternative beverage, but these were probably not as salient as the differences in daily regimen and ways of dosing.

ACTH4-10 has been shown to have effects on some behaviors in the range of 3-6 h (e.g., Fekete \& de Wied, 1982 ), suggesting that it is metabolically inactivated, in the doses tested here and by Krishnan et al. (1991), well before $24 \mathrm{~h}$. It is clear that the short-term effects of ACTH4-10 are more apt to have been extant during the drinking of these tests, since the injections occurred just before the opportunity to drink. There is evidence that drug effects and postdrug effects can affect the propensity to drink alcoholic beverages quite differently (Reid, Delconte, Nichols, Bilsky, \& Hubbell, 1991). Relevant to this issue is the fact that 9 out of the 12 rats that received $30 \mu$ of ACTH4-10 actually increased their intake of the alcoholic beverage from the day of the placebo to the 1st day of dosing.

The rats in this test probably took more ethanol during any 1-h period than did the rats in Krishnan et al. (1991). Therefore, it follows that ACTH4-10 might affect drinking of alcoholic beverages when the amount of alcohol taken is less. However, an inspection of our raw data does not indicate that the rats drinking the least were systematically affected by the effects of ACTH4-10. The rats in these tests had more setting conditions potentiating their intake of alcohol. ACTH4-10 might be effective in reducing intakes when there are fewer conditions motivating intakes (Krishnan et al., 1991).

There is always a problem with obtaining results of no effect, and that problem is exacerbated when other investigators have found an effect. There remains a possibility, for example, that some error was made during our procedures, rendering ACTH4-10 inert. However, there is no reason to conclude that an error was made. Therefore, the conclusion must be drawn that ACTH4-10 did not reliably affect the intake of alcoholic beverages in our testing. Inasmuch as our test is sensitive to the effects of other drugs (which it is) and the results of such testing should predict what kinds of drugs might be effective with people (which, on the basis of limited data, our test does seem to predict), the implication is that preparations of drugs with activity similar to that of ACTH4-10 are not apt to reduce alcoholics' propensity to take alcoholic beverages. On the other hand, the data reported by Krishnan et al. (1991) are impressive.

\section{REFERENCES}

Boнus, B. (1979). Neuropeptide influences on sexual and reproductive behavior. In L. Zichella \& P. Pancheri (Eds.), Development endocrinology: Vol. 5 Psychoneuroendocrinology in reproduction: An interdisciplinary approach (pp. 111-120). Amsterdam: Elsevier.

DE WIED, D., \& Jolles, J. 1982). Neuropeptides derived from proopiocortin: Behavioral, physiological and neurochemical effects. Physiology Reviews, 62, 976-1059.

DE WIED, D., WitTer, A., \& Greven, H. M. (1975). Behaviorally active ACTH analogues. Biochemical Pharmacology, 24, 1463-1468.

FeKeTE, M., \& DE WIED, D. (1982). Potency and duration of action of the ACTH4-9 analog (ORG 2766) as compared to ACTH4-10 and (D-Phe7) ACTH4-10 on active and passive avoidance behavior of rats. Pharmacology, Biochemistry \& Behavior, 16, 387-392.

HUBbeLL, C. L., \& REID, L. D. (1990). Opioids modulate rats' intakes of alcoholic beverages. In L. D. Reid (Ed.), Opioids, bulimia, and alcohol abuse \& alcoholism (pp. 145-174). New York: SpringerVerlag.

Krishnan, S., Nash, J. F., \& Maikel, R. P. (1991). Free-choice ethanol consumption by rats: Effects of ACTH4-10. Alcohol, 8, 401-404.

Naranjo, C. A., Kadlec, K. E., Sanhueza, P., WoodleyRemus, D., \& Sellers, E. M. (1990). Fluoxetine differentially alters alcohol intake and other consummatory behaviors in problem drinkers. Clinical Pharmacology \& Therapeutics, 47, 490-498.

Naranjo, C. A., \& Sellers, E. M. (EDs.). (1985). Research advances in new psychopharmacological treatments for alcoholism. Amsterdam: Excerpta Medica.

Naranjo, C. A., \& Sellers, E. M. (Eds.). (1992). Novel pharmacological interventions for alcoholism. New York: Springer-Verlag.

O'Malley, S. S., Jaffe, A., Chang, G., Witte, G., Schottenfeld, R. S., \& Rounsaville, B. J. (1992). Naltrexone in the treatment of alcohol dependence: Preliminary findings. In C. A. Naranjo \& E. M. Sellers (Eds.), Novel pharmacological interventions for alcoholism (pp. 148-157). New York: Springer-Verlag.

REID, L. D. (ED.) (1990). Opioids, bulimia, and alcohol abuse \& alcoholism. New York: Springer-Verlag.

Reid, L. D., Delconte, J. D., Nichols, M. L., Bilsky, E. J., \& HubBell, C. L. (1991). Tests of opioid deficiency hypotheses of alcoholism Alcohol, 8, 247-257.

REID, L. D., \& HUBBELL, C. L. (1992). Opioids modulate rats' propensities to take alcoholic beverages. In C. A. Naranjo \& E. M. Sellers (Eds.), Novel pharmacological interventions for alcoholism (pp. 121134). New York: Springer-Verlag.

van Nispen, J. W., \& Greven, H. M. (1982). SAR of peptides derived from ACTH, beta-LPH and MSH with regard to avoidance behavior in rats. Pharmacology \& Therapeutics, 16, 67-102.

Volpicelli, J. R., O'Brien, C. P., Alterman, A. I., \& HayaSHIDA, M. (1990). Naltrexone and the treatment of alcohol dependence: Initial observations. In L. D. Reid (Ed.), Opioids, bulimia, and alcohol abuse \& alcoholism (pp. 195-214). New York: SpringerVerlag.

WitTer, A., Greven, H. M., \& DE Wied, D. (1975). Correlation between structure, behavioral activity and rate of biotransformation of some ACTH4-9 analogues. Journal of Pharmacology \& Experimental Therapeutics, 193, 853-860.

(Manuscript received April 27, 1992.) 